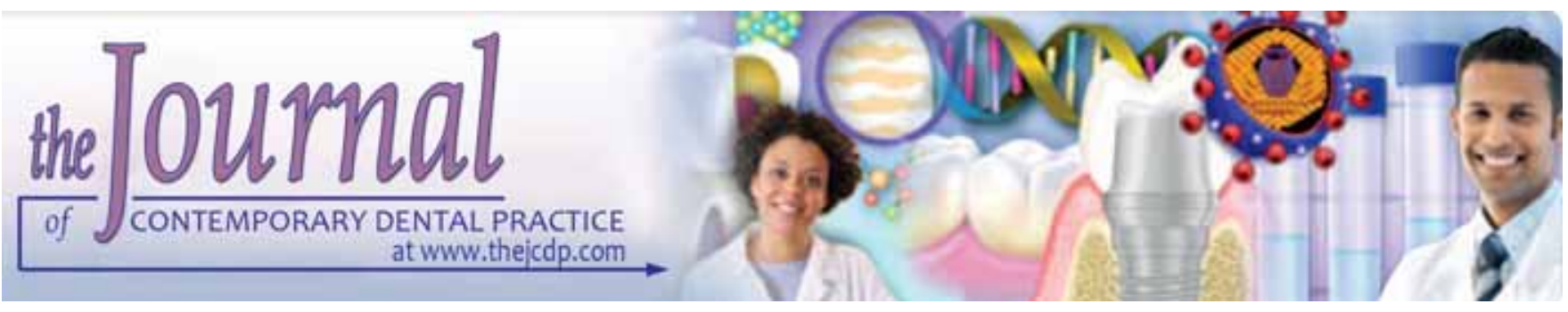

\title{
Effect of Calcium Hydroxide on pH Changes of the External Medium after Intracoronal Bleaching
}

Patrícia Marra de Sá, Raffaela Di lorio Jeronymo, Karen Cristina Kazue Yui, Eduardo Galera da Silva Maria Filomena Rocha Lima Huhtala, Carlos Rocha Gomes Torres, Ana Paula Martins Gomes

\begin{abstract}
Aim: This in vitro study evaluated the effect of calcium hydroxide on $\mathrm{pH}$ changes of the external medium after intracoronal bleaching.

Materials and methods: A total of 50 extracted human premolars were prepared and filled with gutta-percha and endodontic sealer. The teeth were randomly divided into five groups according to the bleaching agents employed: (a) Sterile cotton pellet with distilled water (control group); (b) sodium perborate and distilled water; (c) sodium perborate and $10 \%$ carbamide peroxide; (d) sodium perborate and $35 \%$ hydrogen peroxide; (e) $35 \%$ hydrogen peroxide. The teeth were stored in vials containing distilled water and the $\mathrm{pH}$ values of the medium surrounding the teeth were analyzed. After 7-day storage, the bleaching agent was removed and replaced by calcium hydroxide, and the distilled water was changed, in which the teeth were kept stored for further 14 days. Measurement of $\mathrm{pH}$ of the external medium (distilled water) was performed 7 days after insertion of the bleaching agents, immediately, 7 and 14 days after insertion of the calcium hydroxide. Data were submitted to statistical analysis by the two-way ANOVA and Tukey's test.
\end{abstract}

Results: There were $\mathrm{pH}$ changes of the external medium at 7day period after bleaching procedures. These results confirmed the diffusion of bleaching agents to the external medium.

Conclusion: Calcium hydroxide increased the external medium $\mathrm{pH}$ and was effective for $\mathrm{pH}$ alkalinization after intracoronal bleaching.

Clinical significance: Intracoronal bleaching of endodontically treated teeth may cause cervical root resorption. A possible explanation for this process is the passage of bleaching agents to the periodontal tissues yielding an inflammatory process. In an attempt to keep the neutrality of the periodontal $\mathrm{pH}$, the calcium hydroxide has been recommended. Results of this study showed that this material should be always used after intracoronal bleaching.

Keywords: Tooth bleaching, Dental materials, Sodium perborate, Carbamide peroxide, Hydrogen peroxide, Calcium hydroxide.

How to cite this article: de Sá PM, Jeronymo RDI, Yui KCK, de Silva EG, Huhtala MFRL, Torres CRG, Gomes APM. Effect of Calcium Hydroxide on $\mathrm{pH}$ Changes of the External Medium after Intracoronal Bleaching. J Contemp Dent Pract 2011;12(3): 158-163.

\section{Source of support: Nil}

Conflict of interest: None declared

\section{INTRODUCTION}

Tooth bleaching can avoid more costly and invasive dental treatment, preserving tooth structure. ${ }^{1,2}$ Therefore, whitening is considered a more conservative alternative. Bleaching treatments are affected by a number of factors including the actual cause of tooth discoloration. ${ }^{3}$

Shade alteration of the coronal portion of nonvital teeth may be the result of several factors, such as hemorrhage of the pulpal capillaries due to trauma or surgical removal of the pulp, persistence of necrotic pulp tissue and/or remnants of fillings materials in the pulp chamber ${ }^{4}$ as well as utilization of root canal dressings and sealers. ${ }^{5}$ The trauma to pulpal blood vessels leads to hemorrhage and breakage of hemoglobin, which releases iron. This released iron is combined with hydrogen sulfide and produces iron sulfide, a black component that darkens the tooth. ${ }^{6,7}$ Correct diagnosis of the cause of tooth discoloration is important, as shade changes as a result of different etiologies may require different treatment strategies. ${ }^{7}$

Many of the bleaching systems available use different concentrations and various application forms as the active bleaching agents. ${ }^{8-10}$ Several products have been used in bleaching procedures; however, undesirable side effects, such as tooth discoloration due to reaction products and excessive weakening of the tooth structure, led to abandonment of these materials, with maintenance only of hydrogen peroxide and sodium perborate. Tooth bleaching with hydrogen peroxide has been performed for over 100 years, ${ }^{11,12}$ and the $10 \%$ carbamide peroxide was indicated as a bleaching agent by Haywood and Heymann 
in $1989,{ }^{13}$ in gel presentation, to be applied by the patient in a custom tray.

Intracoronal bleaching of endodontically treated teeth may cause cervical root resorption, besides other problems. ${ }^{10}$ A possible explanation for the process of cervical root resorption would be the passage of bleaching agents to the periodontal tissues through the dentinal tubules, ${ }^{10,14}$ yielding an inflammatory process around the teeth and cervical root resorption. ${ }^{10,14}$ In an attempt to keep the neutrality of the periodontal $\mathrm{pH}$, the association of sodium perborate and water has been recommended to prevent or minimize the occurrence of cervical root resorption. ${ }^{15}$

With a view to interrupt the process of cervical root resorption, Kehoe (1987) indicates the alkalinization of the area affected by resorption by application of calcium hydroxide pastes as a treatment option. ${ }^{16}$

It is suggested that filling of the pulp chamber with calcium hydroxide would increase the $\mathrm{pH}$ of periodontal tissues by ion diffusion, interfering with the osteoclastic activity due to activation of alkaline phosphatases. ${ }^{17}$ In review of the literature, various causes of tooth discoloration, different bleaching agents and their applications in endodontically treated teeth have been described. In the walking bleach technique, the root filling should be completed first, and a cervical seal must be established. The bleaching agent should be changed every 3 to 7 days. ${ }^{18}$

It was established in the literature that the $\mathrm{pH}$ of a $30 \%$ hydrogen peroxide solution is acidic and the $\mathrm{pH}$ of sodium perborate solution is alkaline. ${ }^{19}$ However, the effect of calcium hydroxide for $\mathrm{pH}$ alkalinization of the external medium after intracoronal bleaching needs to be further investigated.

\section{MATERIALS AND METHODS}

This study was approved by the Research Ethics Committee of the São José dos Campos School of Dentistry, UNESP, São Paulo, Brazil. The study sample was composed of 50 single-rooted human premolars recently extracted for orthodontic purposes, which were cleaned with manual instruments and rubber cup with pumice, and immersed in saline solution until used. The teeth were radiographically examined in a mesiodistal and buccolingual directions and visualized under a stereomicroscope for detection of cracks.

Coronal access was performed and the thickness of the buccal wall was standardized at $3 \mathrm{~mm}$, checked with aid of a thickness meter (Bio-Art Equipamentos Odontológicos Ltda, São Carlos, São Paulo, Brazil) in the middle third of the buccal aspect. After pulpectomy, each root canal was enlarged using 1\% sodium hypochlorite solution (Terapêutica, São José dos Campos, São Paulo, Brazil) and Gates-Glidden burs number 3 and 4 (GS Brazil Comercial e Importadora Ltda, São Paulo, Brazil) to create root canals of the same size in the cervical and middle third.
The root canals were prepared and filled using the lateral condensation technique with gutta-percha points (Dentsply Indústria e Comércio Ltda, Petrópolis, Rio de Janeiro, Brazil) and endodontic sealer (Sealapex-Kerr ${ }^{\circledR}$, CA, USA). The filling material was removed to $3 \mathrm{~mm}$ below the cementoenamel junction. A $3 \mathrm{~mm}$ thick intermediate bases of resin-modified glass ionomer cement (Vitremer, 3M, Espe), prepared according to the manufacturer's instructions, was placed at the level of the cementoenamel junction.

The teeth were randomly divided into five groups ( $n=10$ ), being one control group and four experimental groups (Table 1).

\begin{tabular}{cl} 
& \multicolumn{2}{c}{ Table 1: Division of the groups } \\
\hline Study groups & Bleaching agent \\
\hline G1 & $\begin{array}{l}\text { Sterile cotton pellet and distilled water (control } \\
\text { group) }\end{array}$ \\
G2 & $\begin{array}{l}\text { Sodium perborate (Terapêutica, São José dos } \\
\text { Campos, São Paulo, Brazil) and distilled water } \\
\text { (2 gm:1 ml) }\end{array}$ \\
G3 & $\begin{array}{l}\text { Sodium perborate and 10\% carbamide peroxide } \\
\text { (Opalescence, Ultradent Products Inc., South }\end{array}$ \\
& $\begin{array}{l}\text { Jordan, UT, USA) (2 gm:1 ml) } \\
\text { G4 }\end{array}$ \\
& $\begin{array}{l}\text { Sodium perborate and 35\% hydrogen peroxide } \\
\text { (Opalescence Xtra, Ultradent Products Inc., South } \\
\text { Jordan, UT, USA) (2 gm:1 ml) } \\
\text { G5 } \\
\text { 35\% hydrogen peroxide (Opalescence Xtra, } \\
\text { Ultradent Products Inc., South Jordan, UT, USA) }\end{array}$ \\
\hline
\end{tabular}

All materials were weighed on an analytical scale and the bleaching associations were prepared following the proportions. The pulp chamber was filled with the bleaching agents, followed by placement of a piece of absorbent paper (Melitta filter paper, Melitta Brazil, São Paulo, Brazil) adapted to the size of the coronal access. Provisional sealing was performed with Cimpat (Spécialités Septodont, SaintMaur-des-Fossés, France).

The teeth were stored in vials containing $20 \mathrm{ml}$ of distilled water and the $\mathrm{pH}$ values of the medium surrounding the teeth were measured immediately and 7 days after immersion with aid of a pH meter (Digimed DM-20, São Paulo, Brazil). During this period, the teeth were stored in the same medium without change of distilled water or bleaching materials.

After pH measurement at 7-day period, the sealing and bleaching agents were removed and the pulp chamber was irrigated with $5 \mathrm{ml}$ of saline solution. The bleaching agents were replaced by a calcium hydroxide paste (Terapêutica, São José dos Campos, São Paulo, Brazil) prepared with distilled water $(2 \mathrm{gm} / 1 \mathrm{ml})$. The pulp chamber was sealed with temporary cement (Cimpat, Spécialités Septodont, Saint-Maur-des-Fossés, France).

The distilled water was replaced and the $\mathrm{pH}$ was measured before immersion of the teeth. Further $\mathrm{pH}$ measurements were performed immediately, 7 and 14 days 
after filling with calcium hydroxide, without change of distilled water or calcium hydroxide at this period.

\section{Statistical Analysis}

Data were submitted to statistical analysis using Minitab (version 14.12) and Statistica (version 5.5, Stat Soft Inc, Tulsa, OK, USA). Descriptive statistics comprised calculation of mean and standard deviation followed by analysis of variance for repeated measurements (two-way ANOVA) and Tukey's test. The level of significance adopted was $5 \%$.

\section{RESULTS}

The mean $\mathrm{pH}$ values achieved after immersion of the teeth in distilled water (immediately and after 7-day period) are presented in Table 2. The Tukey's test revealed that the control group (G1) differed from the experimental groups for the 7-day period after bleaching procedures (Table 3).

The mean $\mathrm{pH}$ values achieved after insertion of calcium hydroxide are presented in Table 4 . Table 5 presents the results of Tukey's test (5\%) for the time effect.

The mean $\mathrm{pH}$ values achieved with the bleaching procedures at 7 days were compared with the values achieved by filling the pulp chamber with calcium hydroxide at 14-day period (Table 6). Comparison of the procedures (bleaching procedures and placement of calcium hydroxide) within each group by Tukey's test revealed statistically significant differences for all groups, except for G3.

\section{DISCUSSION}

In this study, after 7 days of bleaching, all groups presented an increase in $\mathrm{pH}$ of the external medium, with values higher than 7.0, except for the control group, due to the passage of bleaching agents through the dentinal tubules for the external medium allowing diffusion of hydrogen peroxide.

Dezotti et al (2002) ${ }^{20}$ also observed diffusion of bleaching agents through the cervical root dentin, achieving an increase in $\mathrm{pH}$ of water in which the teeth were stored, except for the control group. The study conducted by Dezotti et al $(2002)^{20}$ demonstrated that the $\mathrm{pH}$ of the paste prepared with $2 \mathrm{gm}$ of sodium perborate powder and $1 \mathrm{ml}$ of $30 \%$ hydrogen peroxide liquid is alkaline. These results agree with the reports of Rotstein and Friedman (1991) ${ }^{21}$ and Chng et al (2002). ${ }^{22}$ Dezotti et al (2002) ${ }^{20}$ did not observe an increased alkalinity with time, in disagreement with the present results, which revealed an increase in $\mathrm{pH}$ from the immediate period to the 7-day period for all associations of sodium perborate. Based on these results, Carrasco et $\mathrm{al}^{23}$ suggested that the use of ultrasonic-activated irrigants in the pulp chamber, before the accomplishment of intracoronal bleaching procedures, may result in a remarkable increase of dentin permeability, which may enhance the efficiency of the whitening agent.

\begin{tabular}{|c|c|c|c|c|c|c|}
\hline Period & G1 (Control) & $G 2(W+S P)$ & $G 3(S P+C P)$ & $G 4(S P+H P)$ & G5 (HP) & Line $($ mean $\pm S D)$ \\
\hline Immediately & $6.53 \pm 0.16$ & $7.03 \pm 0.21$ & $6.72 \pm 0.20$ & $6.95 \pm 0.47$ & $6.44 \pm 0.16$ & $6.73 \pm 0.34$ \\
\hline 7 days & $6.65 \pm 0.23$ & $7.14 \pm 0.35$ & $8.47 \pm 0.58$ & $7.88 \pm 0.52$ & $7.26 \pm 0.20$ & $7.48 \pm 0.75$ \\
\hline Column (mean \pm SD) & $6.59 \pm 0.16$ & $7.09 \pm 0.28$ & $7.60 \pm 0.99$ & $7.42 \pm 0.68$ & $6.85 \pm 0.45$ & \\
\hline
\end{tabular}

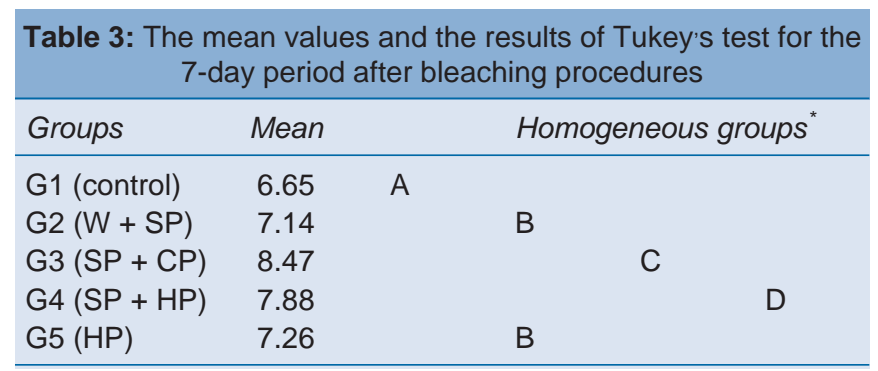

*Means accompanied by the same letters presented no statistically significant differences

\begin{tabular}{lcccccc}
\multicolumn{7}{c}{ Table 4: Mean pH values $( \pm$ standard deviation) achieved after insertion of the calcium hydroxide according to time } \\
\hline Period & $G 1$ (control) & $G 2(W+S P)$ & $G 3(S P+C P)$ & $G 4(S P+H P)$ & $G 5(H P)$ & Line (mean \pm SD) \\
\hline Immediately & $7.48 \pm 0.45$ & $7.45 \pm 0.84$ & $6.91 \pm 0.33$ & $7.12 \pm 0.54$ & $7.81 \pm 0.51$ & $7.35 \pm 0.62$ \\
7 days & $8.54 \pm 0.99$ & $9.70 \pm 0.70$ & $8.56 \pm 1.13$ & $8.77 \pm 1.55$ & $8.77 \pm 0.90$ & $8.87 \pm 1.13$ \\
14 days & $8.52 \pm 1.29$ & $9.64 \pm 0.91$ & $8.88 \pm 1.27$ & $9.32 \pm 2.04$ & $8.76 \pm 1.07$ & $9.02 \pm 1.38$ \\
Column (mean \pm SD) & $8.18 \pm 1.07$ & $8.93 \pm 1.32$ & $8.11 \pm 1.30$ & $8.41 \pm 1.74$ & $8.45 \pm 0.95$ & \\
\hline
\end{tabular}




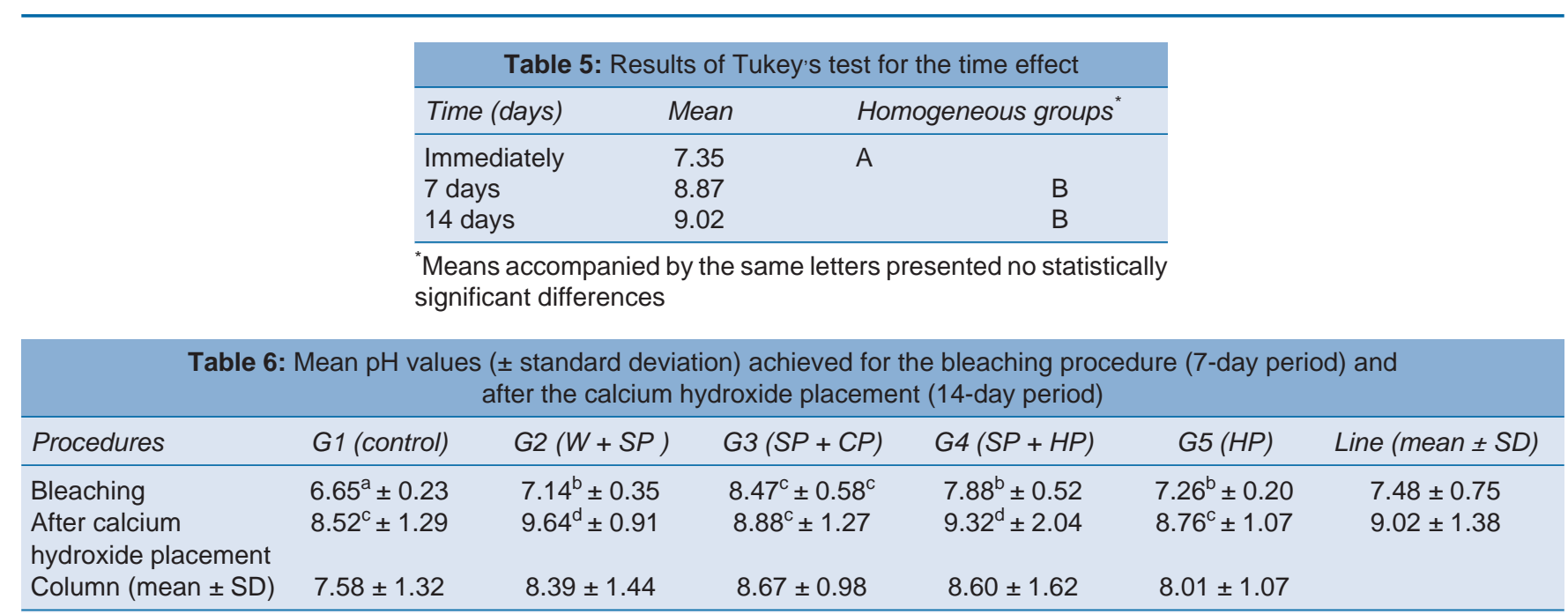

a to $\mathrm{d}$ Means accompanied by the same letters presented no statistically significant differences.

Fuss et al (1989) ${ }^{17}$ evaluated the ability of infiltration of bleaching agents in the pulp chamber through the dentinal tubules, by measurement of $\mathrm{pH}$ changes of the external medium to the root surface. The significant $\mathrm{pH}$ increase of the external medium, from 7.0 to 9.0 in three days, indicated that the bleaching agents penetrated through the dentinal tubules and reached the external medium. However, the study of Fuss et al (1989) ${ }^{17}$ was conducted on young teeth, which present wider dentinal tubules, besides removal of the cervical cementum to simulate a gap between the enamel and cementum at the cervical region.

The 35\% hydrogen peroxide group, which had a slightly acidic $\mathrm{pH}$ at the immediate period, demonstrated an increase in the mean $\mathrm{pH}$ value, leading to alkalinity of the medium after the 7-day period. These results suggest that the hydrogen peroxide employed for intracoronal bleaching without utilization of heat and insertion of an effective cervical barrier would not be a predisposing factor to cervical root resorption.

This study suggests that there was diffusion of bleaching agents with $\mathrm{pH}$ changes of the external medium, in agreement with the results of Fuss et al (1989), ${ }^{17}$ Dezotti et al $(2002)^{20}$ and Chng et al 2002. ${ }^{22}$ Extraradicular diffusion of hydrogen peroxide is inversely proportion to the increase in $\mathrm{pH}$ of the external medium. The amount of hydrogen peroxide detected in the external medium is lower when carbamide peroxide is used compared with the hydrogen peroxide. However, regardless of the bleaching agent employed, there is ion diffusion through the dentinal tubules, with $\mathrm{pH}$ changes of the external medium to the root surface. $^{25}$

According to Pérez $(2001)^{26}$ an aqueous calcium hydroxide paste placed in the pulp chamber increased dentinal $\mathrm{pH}$ more than the other techniques. The dentine $\mathrm{pH}$ is affected by the form of calcium hydroxide used. These
$\mathrm{pH}$ changes of the cementum or dentin adjacent to the cervical periodontal ligament would create a microenvironment unfavorable to the osteoclastic activity, which might revert any demineralization or tissue damage caused by the bleaching procedures and lead to return to an alkaline $\mathrm{pH}$ of the gingival sulcus. However, the placement of calcium hydroxide as a supplementary barrier during intracoronal bleaching did not have a significant effect in reversing the acidic $\mathrm{pH}$ created at the external root surface in vitro. Its potential effect during these procedures in vivo needs to be further investigated. ${ }^{24}$

In the present study, after calcium hydroxide placement in the pulp chamber there was an increase in $\mathrm{pH}$ of the external medium between the immediate, 7 and 14 days period. However, this change was not significant after a 7-day interval. During this period, the color of the bleached tooth should be stable and a calcium hydroxide dressing placed in the pulp chamber for buffering the acid $\mathrm{pH}$ that can occur on cervical root surfaces after intracoronal application of bleaching agents. ${ }^{27}$ The calcium hydroxide suspension temporarily placed into the pulp chamber after completion of the bleaching procedures does not interfere with the adhesion of composite materials used for final restoration of the access cavity. ${ }^{18,28}$

With regard to the 14-day period effect of calcium hydroxide on $\mathrm{pH}$ of the external medium, there was a significant increase in $\mathrm{pH}$ of all groups, suggesting that calcium hydroxide would be efficient for alkalinization of the medium after intracoronal bleaching. However, for the group composed by sodium perborate and carbamide peroxide, the effect of calcium hydroxide was not significant, probably due to the high $\mathrm{pH}$ of the external medium observed for this group at completion of 7-day period of intracoronal bleaching.

Intracoronal bleaching has emerged as a popular technique to bleach discolored, endodontically treated 
anterior teeth. Although hydrogen peroxide and sodium perborate have traditionally been used in intracoronal bleaching, some concern has been expressed regarding the use of hydrogen peroxide, mainly because of the suspected 'cause and effect' relationship between hydrogen peroxide and invasive cervical root resorption. Other complications associated with use of hydrogen peroxide alone or in combination with sodium perborate include increased dentine permeability, alteration in the chemical structure of dentine and general weakening of physical properties of dental hard tissues. This has prompted researchers to look for alternative bleaching agents as effective as the traditional bleaching agents but unassociated with such complications. Some of these alternatives have been shown to be as effective as sodium perborate in lightening tooth color under in vitro conditions and may represent a useful alternative to the traditional materials that are currently in use. ${ }^{22}$

Today, the intracoronal bleaching of nonvital discolored teeth is a low-risk routine treatment for improving esthetics. However, the insufficient cervical sealing and high concentrations of bleaching agents should be avoided, as this can increase the risk of cervical root resorption. The risk of cervical root resorption should be discussed with the patient. ${ }^{29}$

\section{CONCLUSION}

The bleaching agents employed, changed the $\mathrm{pH}$ of the external medium at 7-day period. Calcium hydroxide increased the external medium $\mathrm{pH}$ and was effective for $\mathrm{pH}$ alkalinization after intracoronal bleaching.

\section{REFERENCES}

1. Teixeira EC, Turssi CP, Hara AT, Serra MC. Influence of postbleaching time intervals on dentin bond strength. Braz Oral Res 2004;18:75-79.

2. Haywood VB. Bleaching of vital and nonvital teeth. Curr Opin Dent 1992;2:142-49.

3. Burrows S. A review of the safety of tooth bleaching. Dent Update 2009;36:604-06, 608-10, 612-14.

4. Freccia WF, Peters DD. A technique for staining extracted teeth: A research and teaching aid for bleaching. J Endod 1982;8:67-69.

5. McEvoy SA. Chemical agents for removing intrinsic stains from vital teeth. Technique development. Quintessence Int 1989;20:323-28.

6. Macey-Dare LV, Williams B. Bleaching of a discoloured nonvital tooth: Use of a sodium perborate/water paste as the bleaching agent. Int J Paediatr Dent 1997;7:35-38.

7. Yui KCK, Rodrigues JR, Mancini MNG, Balducci I, Goncalves SEP. Ex vivo evaluation of the effectiveness of bleaching agents on the shade alteration of blood-stained teeth. Int Endod J 2008;41:485-92.

8. Uysal T, Basciftci FA, Usumez S, Sari Z, Buyukerkmen A. Can previously bleached teeth be bonded safely? Am J Orthod Dentofacial Orthop 2003;123:628-32.

9. Turkun M, Kaya AD. Effect of $10 \%$ sodium ascorbate on the shear bond strength of composite resin to bleached bovine enamel. J Oral Rehabil 2004;31:1184-91.

10. Dahl JE, Pallesen U. Tooth bleaching - a critical review of the biological aspects. Crit Rev Oral Biol Med 2003;14:292-304.
11. Kugel G, Papathanasiou A, Williams AJ, Anderson C, Ferreira S. Clinical evaluation of chemical and light-activated tooth whitening systems. Compend Contin Educ Dent 2006;27:54-62.

12. Davidi MP, Hadad A, Weiss EI, Domb A, Mizrahi B, Sterer N. The effect of a mild increase in temperature on tooth bleaching. Quintessence Int 2008;39:771-75.

13. Haywood VB, Heymann HO. Nightguard vital bleaching. Quintessence Int 1990;20:173-76.

14. Heller D, Skriber J, Lin LM. Effect of intracoronal bleaching on external cervical root resorption. J Endod 1992;18:145-48.

15. Ari $\mathrm{H}$, Ungor $\mathrm{M}$. In vitro comparison of different types of sodium perborate used for intracoronal bleaching of discoloured teeth. Int Endod J 2002;35:433-36.

16. Kehoe JC. pH reversal following in vitro bleaching of pulpless teeth. J Endod 1987;13:6-9.

17. Fuss Z, Szajkis S, Tagger M. Tubular permeability to calcium hydroxide and to bleaching agents. J Endod 1989;15:362-64.

18. Plotino G, Buono L, Grande NM, Pameijer CH, Somma F. Nonvital tooth bleaching: A review of the literature and clinical procedures. J Endod 2008;34:394-407.

19. Rotstein I. In vitro determination and quantification of $30 \%$ hydrogen peroxide penetration through dentin and cementum during bleaching. Oral Surg Oral Med Oral Pathol 1991;72:602-06.

20. Dezotti MS, Souza Jr MH, Nishiyama CK. Evaluation of pH variation and cervical dentin permeability in teeth submitted to bleaching treatment. Pesqui Odontol Bras 2002;16:263-68.

21. Rotstein I, Friedman S. pH variation among materials used for intracoronal bleaching. J Endod 1991;17:376-79.

22. Chng HK. Update on materials used in intracoronal bleaching. Ann R Australas Coll Dent Surg 2002;16:147-50.

23. Carrasco LD, Pecora JD, Froner IC. In vitro assessment of dentinal permeability after the use of ultrasonic-activated irrigants in the pulp chamber before internal dental bleaching. Dent Traumatol 2004;20:164-68.

24. Lambrianidis T, Kapalas A, Mazinis M. Effect of calcium hydroxide as a supplementary barrier in the radicular penetration of hydrogen peroxide during intracoronal bleaching in vitro. Int Endod J 2002;35:985-90.

25. Lee GP, Lee MY, Lum SO, Poh RS, Lim KC. Extraradicular diffusion of hydrogen peroxide and $\mathrm{pH}$ changes associated with intracoronal bleaching of discoloured teeth using different bleaching agents. Int Endod J 2004;37:500-06.

26. Perez F, Franchi M, Peli JF. Effect of calcium hydroxide form and placement on root dentine pH. Int Endod J 2001;34:417-23.

27. Baratieri LN, Ritter AV, Monteiro Jr S, Andrada MAC, Vieira LCC. Nonvital tooth bleaching: Guidelines for the clinician. Quintessence Int 1995;26:597-608.

28. Demarco FF, Freitas JM, Silva MP, Justino LM. Microleakage in endodontically treated teeth: Influence of calcium hydroxide dressing following bleaching. Int Endod J 2001;34:495-500.

29. Zimmerli B, Jeger F, Lussi A. Bleaching of nonvital teeth. A clinically relevant literature review. Schweiz Monatsschr Zahnmed 2010;120:306-20.

\section{ABOUT THE AUTHORS}

\section{Patrícia Marra de Sá}

Postgraduate Student, Department of Restorative Dentistry, São José dos Campos School of Dentistry, UNESP São Paulo State University São Paulo, Brazil

\section{Raffaela Di lorio Jeronymo}

Postgraduate Student, Department of Restorative Dentistry, São José dos Campos School of Dentistry, UNESP São Paulo State University São Paulo, Brazil 


\section{Karen Cristina Kazue Yui}

Assistant Professor, Department of Restorative Dentistry, São José dos Campos School of Dentistry, UNESP São Paulo State University São Paulo, Brazil

\section{Eduardo Galera da Silva}

Assistant Professor, Department of Restorative Dentistry, São José dos Campos School of Dentistry, UNESP São Paulo State University São Paulo, Brazil

\section{Maria Filomena Rocha Lima Huhtala}

Assistant Professor, Department of Restorative Dentistry, São José dos Campos School of Dentistry, UNESP São Paulo State University São Paulo, Brazil

\section{Carlos Rocha Gomes Torres}

Assistant Professor, Department of Restorative Dentistry, São José dos Campos School of Dentistry, UNESP São Paulo State University São Paulo, Brazil

\section{Ana Paula Martins Gomes}

Associate Professor, Department of Restorative Dentistry, São José dos Campos School of Dentistry, UNESP São Paulo State University São Paulo, Brazil

\section{CORRESPONDING AUTHOR}

Raffaela Di Iorio Jeronymo, Avenida Engenheiro Francisco José Longo, 777, Jardim São Dimas, São José dos Campos, São Paulo, CEP12245-000, Brazil, Phone: +55 (12) 39479048, e-mail: raffadi@ig.com.br 